\title{
ESTUDANTES EGRESSOS DA ESCOLA PÚBLICA NO ENSINO SUPERIOR: UM OLHAR GEOGRÁFICO
}

\author{
Juliana Nóbrega de Almeida ${ }^{1}$, Francisco Kennedy Silva dos Santos ${ }^{2}$
}

\begin{abstract}
${ }^{1}$ Doutora em Geografia pelo PPGeo UFPE, Professora do Departamento de Geografia da Universidade Estadual da Paraíba do campus de Guarabira; E-mail: julianageo2020@gmail.com
\end{abstract}

2 Professor do Programa de Pós-Graduação em Geografia da UFPE. Bolsista de Produtividade em Pesquisa 2 do CNPQ

Artigo recebido em 16/08/2020 e aceito em 01/12/2020

\begin{abstract}
RESUMO
Esse artigo tem como objeto central uma análise propositiva dos mecanismos de acesso e permanência no ensino superior como construtores e modeladores de sistemas territoriais possíveis de inclusão. Elegemos a Universidade Federal de Campina Grande (UFCG) como recorte para compreensão de campos de limitação e possibilidades de acesso e permanência de alunos egressos da educação básica da rede pública de ensino. Assim, as questões trazidas nessa investigação têm a intenção de contribuir para a compreensão dos desafios diante do acesso e da permanência dos estudantes egressos da escola pública na educação superior. Portanto, com essa pesquisa, buscamos mobilizar o interesse dos pesquisadores da Ciência Geográfica e de áreas afins, diante da construção dos processos de inclusão, numa vertente social e educacional, com o propósito de construirmos espacialidades menos desiguais junto aos espaços acadêmicos, promovendo cidadania e emancipação por meio do acesso e da permanência mais democráticos às instituições de ensino superior.
\end{abstract}

Palavras-chave: Educação superior; Acesso; Permanência; Cidadania; Olhar Geográfico.

\section{STUDENTS EGRESSED FROM PUBLIC SCHOOL IN HIGHER EDUCATION: A GEOGRAPHICAL VIEW}

\begin{abstract}
This article has as central object a propositive analysis of the mechanisms of access and permanence in higher education as builders and modelers of possible territorial systems of inclusion. We have elected the Federal University of Campina Grande as a cutout for understanding the fields of limitation and possibilities of access and permanence of students and graduates of basic education in the public education network. Thus, the issues brought in this research have the intention of contributing to the understanding of the challenges facing the access and permanence of students and graduates of the public school in Higher Education. Therefore, with this research we seek to mobilize the interest of researchers in Geography and related areas, faced with the construction on inclusion processes, in and educational aspect, with the purpose of building less unequal spatialities in academic spaces, promoting citizenship and emancipation through more democratic access and permanence to Institutes of Higher Education.
\end{abstract}

Keywords: Higher education; Access; Permanence; Citizenship; Geographical view. 


\section{INTRODUÇÃO}

O artigo em tela é um recorte de uma pesquisa de Doutorado, tendo como objetivo construir uma reflexão sobre os mecanismos utilizados para estimular o acesso e a permanência dos estudantes egressos da escola pública junto à educação superior, promovida em Campina Grande PB, no campus sede da Universidade Federal de Campina Grande (UFCG).

Assim, buscamos entender o processo de espacialização da educação superior pública, um tema pouco estudado dentro da Ciência Geográfica, bem como as suas principais caraterísticas ligadas ao acesso e à permanência no campus sede da UFCG. Destacamos, dessa maneira, que essa discussão é relevante e deve ganhar mais atenção dentro da nossa ciência, sobretudo por que a produção do espaço e seus fenômenos também ocorrem dentro do âmbito universitário.

A Geografia nos mostra que a produção do espaço se dá em múltiplos lugares, inclusive nos ambientes educacionais, onde existe uma concentração de diversas tipologias de sujeitos (representada especialmente por seus estudantes. Por isso, trazemos, na pesquisa, um diálogo no qual buscamos discorrer, por meio do olhar geográfico, sobre esse fenômeno.

Escolhemos como cenário Campina Grande - PB, município que recebe o título de cidade universitária por concentrar importantes Institutos de Ensino Superior (IES) públicos e privados, sendo reconhecida não só na Paraíba, mas em todo o Nordeste como relevante por promover o ensino superior, a pesquisa e a extensão, atendendo a estudantes de várias espacialidades para além da região.

No entanto, nem todos os moradores de Campina Grande podem desfrutar desse benefício, especialmente aqueles que são oriundos da escola pública e de baixa renda, uma vez que o acesso à universidade pública não é para todos, uma vez que a quantidade de vagas é limitada. Por isso as vagas são destinadas aos estudantes que alcançarem as maiores notas no processo seletivo utilizado para o seu acesso, o Exame Nacional do Ensino Médio (ENEM).

Essa contradição promove espaços educacionais distintos e "oportunidades" diferentes diante do mundo acadêmico para os estudantes, formando territórios, pois estabelece relações com indivíduos e grupos sociais marcados por elementos que pressupõem uma relação de poder, representados, nesse estudo, pela conquista do Ensino Superior, sendo este um modo geográfico de construir o espaço.

Metodologicamente, esta pesquisa partiu de uma abordagem qualitativa e quantitativa com viés bibliográfico (estado da arte), documental e de campo. Alguns dos autores que alicerçaram a nossa discussão foram Almeida (2019), Palácio (2012), Dourado (2002), Chauí (2003), entre outros, 
junto ao objeto de estudo. Na pesquisa in loco, foram realizadas entrevistas semiestruturadas com um total de cinco professores, representantes do Centro de Ciências Biológicas e da Saúde (CCBS), do Centro de Engenharia Elétrica e Informática (CEEI), do Centro de Humanidades (CH), do Centro de Ciências Tecnológicas (CCT) e do Centro de Tecnologia e Recursos Naturais (CTRN). Além disso, entrevistamos representantes da Pró-Reitoria de Assuntos Comunitários (PRAC) e da Pró-Reitoria de Pesquisa e Extensão.

Também aplicamos questionários semiestruturados a estudantes egressos da escola pública pertencentes aos cursos dos cinco Centros Acadêmicos mencionados. Seguimos uma amostra do tipo não-probabilística intencional, em que os seus elementos são selecionados de acordo com a intenção do pesquisador. Para determinação da amostra com o universo desconhecido, foi utilizada a fórmula encontrada em Sâmara e Barros (1997, p. 75), que resultou uma amostra de 196 estudantes pertencentes aos cinco Centros da UFCG, em seu campus sede.

Para analisarmos as entrevistas foram realizadas com os professores e funcionários, juntamente com as repostas subjetivas dos questionários aplicados com os estudantes, foi utilizado o IRaMuTeQ, um software que viabiliza diferentes tipos de análise de dados textuais, abrangendo lematização (processo que reduz as palavras com base em suas raízes - formas reduzidas) e o cálculo de frequência de palavras, também gerando análises multivariadas, como classificação hierárquica descente de seguimentos de textos, análise de correspondências e analises de similitude (CAMARGO; JUSTO, 2013). Assim, no âmbito da Ciência Geográfica, esta é uma das primeiras investigações no cenário nacional que propõem um estudo sobre tal temática.

Motivados pelo fato de que os estudantes vindos da escola pública estiveram, por muito tempo, excluídos ou tinham acesso reduzido à educação superior, propomos construir uma reflexão através das lentes da Geografia. Sobre esse fato a problemática desta pesquisa aponta que um grande número de jovens que concluíram a educação básica não se insere nos IES de Campina Grande devido à existência de um sistema de produção educacional que impõe diversas barreiras, de ordem social, econômica e cultural.

Também foi relatado pelos professores e estudantes um déficit de aprendizagem, bem como problemas relacionados a bagagem dos conteúdos do ensino fundamental e médio por parte de uma parcela expressiva de estudantes. Esses e outros fatores alimentam a distância entre as universidades e a escola pública, sendo necessário que existam mais pesquisas que se debruçam sobre o tema exposto. 


\section{ACESSO DOS ESTUDANTES EGRESSOS DA ESCOLA PÚBLICA NO ENSINO SUPERIOR: ALGUMAS REFLEXÕES}

De acordo com Dourado et al (2002), o Brasil, nos primeiros anos no século XXI, vivenciamos um aumento das matrículas no ensino superior. Assim, evidencia-se que, no setor público, também ocorreu uma ampliação das vagas, sobretudo nos Institutos Federais de Ensino Superior (IFES), porém menor do que no setor privado. O que estimulou o aumento das vagas no Ensino Superior nos institutos públicos foi o Programa de Apoio a Planos de Reestruturação e Expansão das Universidades Federais $\left(\mathrm{REUNI}^{1}\right)$, que buscaram ampliar não apenas o acesso, mas também a permanência dos estudantes.

Para Palácio (2012), o Governo Federal aprovou o REUNI por meio do Decreto n. 6.096, de 24 de abril 2007, com o objetivo de criar condições para a ampliação do acesso e da permanência na educação superior, no nível de graduação, além de melhorar o aproveitamento da estrutura física e de recursos humanos das universidades federais, respeitando as peculiaridades regionais de cada Instituto Federal de Ensino Superior (IFES). O referido programa contribuiu para a expansão das vagas, a criação de cursos e a implantação de centros de ensino e campi universitários, além de possibilitar a contratação de docentes e de técnicos administrativos para dar suporte à expansão universitária.

O REUNI consolidou também um novo modelo de inserção à assistência estudantil, tendo em vista que suas diretrizes tiveram impacto direto na regulamentação do Plano Nacional de Assistência Estudantil, formulado pelo Fonaprace, em 2007, e na sua posterior institucionalização pelo Decreto n. 7.234, de 19 de julho de 2010, que instituiu o Programa Nacional de Assistência Estudantil/PNAES (NASCIMENTO, 2013).

Dourado, Oliveira e Santos (2007) acrescentam que nossa defasagem em relação ao acesso ao ensino superior é constrangedora se comparada à situação de outros países latino-americanos: Argentina, Venezuela, Uruguai e Costa Rica apresentam percentual maior que 30\% nas matrículas. Outro dado alarmante é a permanência da elitização e da seletividade social e étnica no acesso ao ensino superior.

Segundo dados do INEP (2016), o número de estudantes no ensino superior aumentou gradualmente se compararmos os anos entre 2006 e 2016. Em termos quantitativos, os indicadores da pesquisa feita pelo INEP apresentam um maior número de matriculas nesse nível de ensino. O acesso desses novos estudantes no ensino superior contou com a parceria de investimentos públicos

\footnotetext{
${ }^{1}$ Criado pelo Decreto n. 6.096, de 24 de abril 2007.
} 
no setor privado, a partir do Programa de Financiamento Estudantil (FIES) ${ }^{2}$ e do Programa Universidade para Todos (PROUNI) ${ }^{3}$, enquanto os IFES e IES públicos apresentam em torno de $25 \%$ do total de matriculas nesse nível de ensino.

De acordo com Palácio (2012), um dos motivos que promoveu o aumento do número de vagas no ensino superior privado ocorreu porque os IES públicos não possuíam condições de atender a demanda de estudantes. Esse fato aumentou o crescimento e o surgimento de várias IES particulares, cuja qualidade, com algumas exceções, é questionável. Enquanto isso, o ensino básico público ainda não possui aparelhagem suficiente para qualificar o egresso nas instituições melhores qualificadas.

Dessa forma, ter acesso à universidade é um sonho para muitos estudantes, inclusive para os egressos da escola pública e para as suas famílias. No entanto, nem todos os estudantes que se inserem no ensino superior público permanecem e concluem o seu curso. Infelizmente, muitos estudantes abandonam, desistem, trancam ou transferem seu curso para outros IES, deixando de se graduar.

Retomando os dados do INEP (2016), no ano de 2006, 195.123 estudantes se graduaram no ensino superior público e 565.402 se graduaram no ensino superior privado. Já em 2016, tivemos um crescimento em ambos os setores. No setor público, graduaram-se 246.875 estudantes, enquanto no ensino superior privado esse número alcançou 922. 574 (ALMEIDA, 2019).

Podemos refletir que o aumento nos estudantes que se graduam no ensino superior privado é muito maior, já que entre os anos de 2006 e 2016 tivemos um aumento de mais de 90\%, o que nos leva a afirmar que de cada quatro estudantes que conseguem se graduar no Brasil, três deles são oriundos do ensino superior privado e apenas um estudante é do ensino superior público. Nessa perspectiva, alguns estudantes não conseguem alcançar a pontuação suficiente nos exames de admissão para terem acesso aos Institutos de Ensino Superior públicos e acabam optando pelo ensino superior privado, especialmente pelo incentivo do FIES e do PROUNI.

Nesse cenário, existem muitos estudantes que possuem dificuldades para acompanhar o conteúdo do curso de graduação escolhido. Com a base no estudo de Palácio (2012), esse motivo leva alguns estudantes a se evadirem da universidade pública e a procurar opções em faculdades de ensino superior particulares, por meio de bolsas e financiamentos do Governo Federal. Logo, a ampliação do acesso ao ensino superior se deu de maneira muito mais volumosa no sistema privado,

\footnotetext{
${ }^{2}$ Financiamento Estudantil, realizado em parceria entre o Governo Federal e IES privados.

${ }^{3}$ Programa Universidade para Todos, criado pelo Ministério da Educação para ampliar o acesso dos estudantes ao ensino superior, que oferece bolsas de estudos em IES particulares.
} 
"legitimando uma falsa democratização e um efeito socialmente perverso, com prioridade para a inserção precária dos pobres no espaço privado" (CATANI; HEY; GILIOLI, 2006; NEVES et al., 2007).

Analisando o percentual de matriculas por rede pública/privada dos estados brasileiros em relação ao total de vagas da Federação Brasileira, podemos destacar que a Paraíba se apresenta como um dos menores percentuais, com 0,9\%. Esse dado pode ser questionado quando observamos os dados do IBGE, que informa que para cada 100 mil habitantes, a Paraíba é o Estado que possui o maior número de vagas no ensino superior. A Paraíba tem a maior taxa do Nordeste de matrículas da população de 18 a 24 anos na educação superior, segundo o Anuário Brasileiro da Educação Básica 2016, que tem dados dos Estados até 2014.

Para Palácio (2012), a maioria dos discentes que conseguem ter acesso à universidade pública o teve sob as atuais condições de fragilidade estruturais e pedagógicos da educação básica. Por isso, enquanto o ensino básico público não tiver aparelhagem suficiente para qualificar o seu egresso. Dessa maneira, políticas públicas de acesso e permanência são necessárias no conjunto das ações de investimento dos IES.

Nesse sentido, a pesquisa buscou conhecer o acesso e a permanência dos alunos oriundos da escola pública de maneira geral na UFCG, junto aos processos de inclusão e cidadania, não escolhendo apenas um curso superior para esse fim. Por isso, dentre os respondentes do nosso questionário, temos estudantes dos cinco centros da UFCG, em seu campus sede, dos cursos de Administração, Engenharia Civil, Engenharia Mecânica, Engenharia Elétrica, Engenharia Agrícola, Engenharia Química, Ciência da Computação, Economia, Arte e Mídia, Geografia, Letras, Pedagogia, Ciências sociais, Medicina, Psicologia Economia e Matemática.

Buscamos traçar algumas características pertinentes referentes aos aspectos socioeducacionais dos estudantes da UFCG, egressos da escola pública, pertencente aos cursos de graduação do Centro de Ciências Biológicas e da Saúde (CCBS), do Centro de Engenharia Elétrica e Informática (CEEI), do Centro de Humanidades (CH), do Centro de Ciências Tecnológicas (CCT) e do Centro de Tecnologia e Recursos Naturais (CTRN). Dentre as questões que buscamos conhecer, damos destaque à faixa etária dos estudantes, observando que $43 \%$ possuem entre 21 e 25 anos de idade, $27 \%$ possuem de 26 a 30 anos de idade, $20 \%$ possuem de 17 a 20 anos de idade, e os demais $10 \%$ possuem acima de 31 anos de idade, como é possível observar no gráfico 1.

Dessa maneira, temos um grande percentual de jovens inseridos no ensino superior em Campina Grande, na UFCG. Tal resultado estatístico nos mostra que o número de estudantes jovens 
é bastante relevante, com $60 \%$ dos estudantes participantes da pesquisa possuindo menos de 25 anos de idade.

Gráfico 1: Faixa etária dos estudantes respondentes.

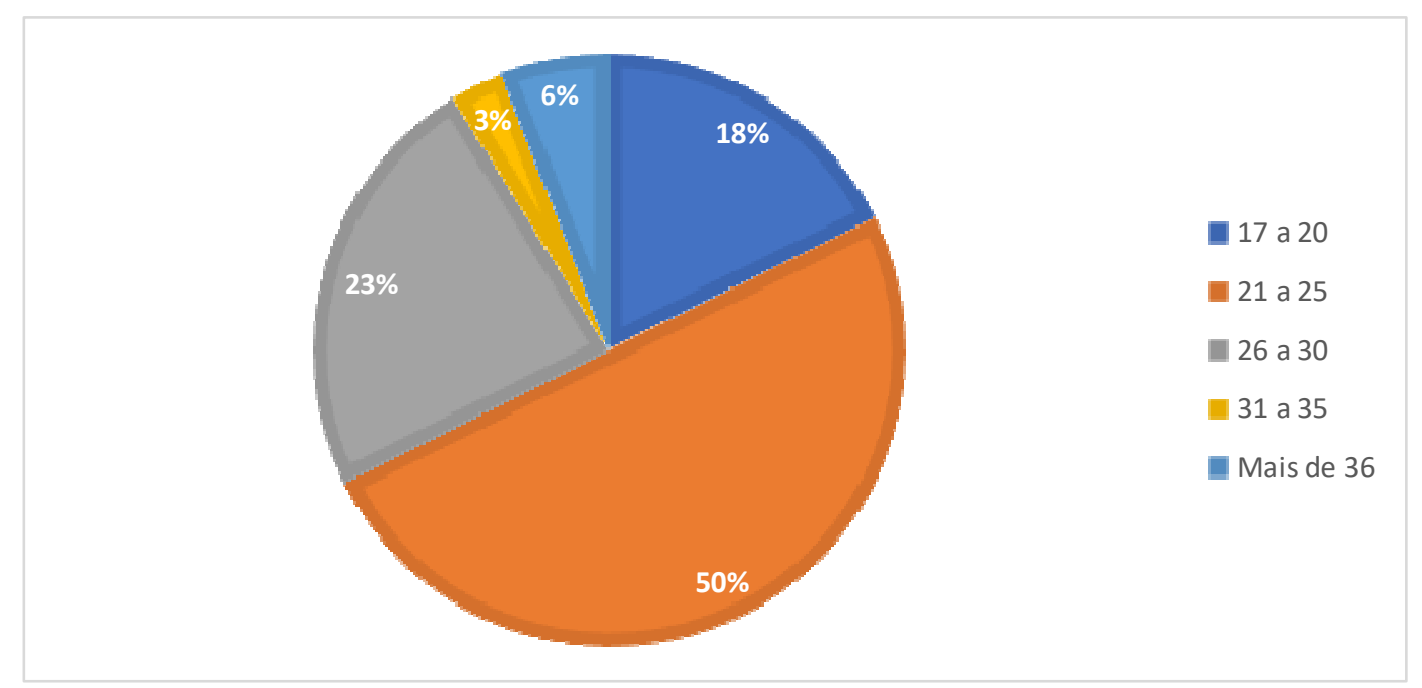

Fonte: Acervo da pesquisa, 2018.

Em relação ao turno de matricula dos estudantes respondentes do nosso questionário, 57\% são estudantes do período diurno e $43 \%$ são matriculados no turno da noite. Buscamos, junto à pesquisa de campo, ter o maior número possível de estudantes dos dois turnos. Dessa forma, de acordo com o nosso questionário, $56 \%$ dos estudantes se declaram pertencentes ao gênero masculino e $44 \%$ ao gênero feminino. Precisamos destacar que os estudantes foram escolhidos de maneira aleatória, não tínhamos intenção de priorizar um gênero especifico sobre o outro.

Buscamos também conhecer o local de moradia dos estudantes. Dessa forma, $56 \%$ dos respondentes são moradores de Campina Grande e $44 \%$ residem em outros municípios. Um fato importante que precisamos mencionar é que muitos estudantes que residem em Campina Grande são oriundos de outros Municípios e Estados, residindo na cidade apenas para estudarem. Segundo os relatos dos estudantes, eles moram em residências de familiares, em republicas ou dividem a moradia que, na maioria dos casos, é alugada com outros estudantes que se fixaram em Campina Grande.

Em relação aos discentes residentes em outros municípios, notamos que uma grande parcela viaja diariamente para poder estudar na UFCG, muitos inclusive são oriundos de outros Estados, a exemplo de Pernambuco. Outra característica relevante é que esses estudantes que residem em outros municípios são matriculados na maioria dos casos no turno da noite, vários deles trabalhando para custear suas despesas com a universidade e estudam no turno da noite. 
Quando perguntados se os estudantes percebiam/sentiam a UFCG como seu espaço de vivência e pertencimento, $87 \%$ responderam que sim e $13 \%$ responderam que não sentiam. Nas conversas durante a pesquisa de campo, eles mencionaram que sentem a UFCG como um lugar relevante para as suas vidas. Muitos, inclusive, disseram que a UFCG era a sua segunda casa, pois passavam muitas horas diariamente na universidade.

Nesse sentido, o tempo dentro da universidade também foi um fator para que alguns estudantes demonstrem não sentir a UFCG como seu espaço de vivência, principalmente os discentes do turno da noite, pois, segundo eles, não podem se dedicar exclusivamente à universidade, devido à sua moradia distante ou porque trabalham ao longo do dia, segundo uma parcela importante dos respondentes eles deixam muitas vezes de participar de ações importantes da vida acadêmica, devido a essa circunstancias, como: projetos, extensão, grupos de pesquisa e reuniões de grupos de estudo.

De acordo com a pesquisa de campo, a grande maioria dos estudantes respondentes do nosso questionário não trabalha, representando $71 \%$. Diante do grande número de estudantes que não trabalham, percebemos que as dificuldades financeiras formam um dos grandes entraves para a sua permanência e a sua manutenção na UFCG. Uma parcela expressiva desses discentes é assistida pela Pró-Reitoria de Assuntos Comunitários (PRAC), porém nem todos recebem algum tipo de auxílio financeiro ou material da universidade. Dessa forma, as suas famílias, que, na maioria dos casos, são assalariadas ou subempregadas, precisam mantê-los em seus cursos universitários.

Já os outros $29 \%$ dos respondentes que trabalham, buscam conciliar o binômio emprego/educação. Esse binômio, segundo os relatos dos estudantes durante a pesquisa de campo, não é positivo, pois tem levado à evasão de alguns estudantes, que optam em trabalhar, abandonando seu curso superior, pois sentem dificuldades em conciliar seus horários de estudo e trabalho.

Procuramos conhecer como os estudantes se mantêm financeiramente para estudar. Assim, $26 \%$ são mantidos financeiramente por suas famílias, $26 \%$ possuem alguma assistência estudantil (como acesso ao Restaurante Universitário, bolsa do Programa de Auxílio ao Ensino de Graduação (PAEG), auxílio-moradia, dentre outros), 25\% possuem algum tipo de bolsa de ensino, pesquisa ou extensão (de programas como Programa Institucional de Bolsas de Iniciação à Docência (PIBID), Programa Institucional de Bolsas de Iniciação Científica (PIBIC), Programa de Educação Tutorial (PET) e Residência Pedagógica), 20\% destacaram que trabalham e 3\% possuem outras formas de atividades para se manter estudando, como é possível vermos no gráfico 2. 
Gráfico 2: Formas de se manter estudando dos estudantes da UFCG

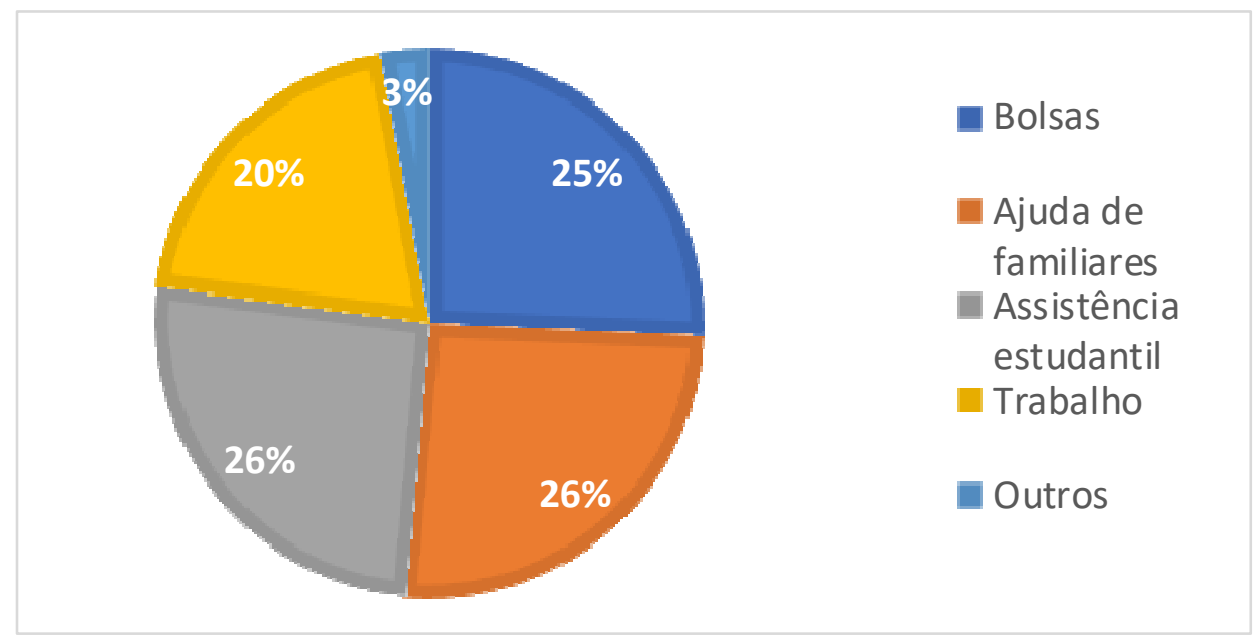

Fonte: Acervo da pesquisa, 2018.

Segundo Almeida (2019), a assistência estudantil desempenha seu papel fundamental na permanência dos estudantes das camadas populares na educação superior, por isso as universidades federais possuem uma política que estimula a permanência dos estudantes desenvolvida pelo Programa Nacional de Assistência Estudantil (PNAES) ${ }^{4}$. De acordo com o Art. $2^{\circ}$, são objetivos do PNAES (BRASIL, 2010) democratizar as condições de permanência dos jovens na Educação Superior Pública Federal, minimizando os efeitos das desigualdades sociais e regionais na permanência e na conclusão da educação superior, também reduzindo as taxas de retenção e evasão e contribuindo para a promoção da inclusão social pela educação.

Em relação as questões raciais, os estudantes respondentes se autodeclararam 56\% pardos, $25 \%$ brancos, $19 \%$ pretos e $3 \%$ indígenas. Essa realidade tem suas raízes nos processos culturais da formação do território brasileiro. Os dados da tese confirmam os números oficias sobre as questões raciais no Brasil, junto a educação superior, no qual temos uma parcela ainda pequena de pessoas pretas e indígenas nas universidades públicas brasileiras, conforme afirma o Instituto Brasileiro de Geografia e Estatística (IBGE, 2019).

\section{CIDADANIA E UNIVERSIDADE NA CONSTRUÇÃO DE CONSCIÊNCIA SOCIAL}

Na visão de Santos (2002), a escola e a universidade possuem um grande papel na criação dos fermentos que conduzem à ampliação do grau de consciência social; por isso, tais âmbitos são

\footnotetext{
${ }^{4}$ Decreto n. 7.234 (BRASIL, 2010), que estabelece o PNAES, executado no âmbito do MEC, tendo como finalidade ampliar as condições de permanência dos jovens na Educação Superior Pública Federal. O documento estabelece também que caberá a cada instituição federal de ensino superior definir os critérios e a metodologia de seleção dos alunos de graduação a serem beneficiados.
} 
considerados espaços de revelação e lugar das grandes mutações e transformações da sociedade, territórios de educação e formação profissional. De acordo com Serpa (2017), os territórios podem ser entendidos como modos de manifestação do ser-no-mundo, pois o território tem a ver com posse e domínio, por meio de relação com o cotidiano, dialeticamente complementado por outros pares dialéticos: igualdade/diferença, hegemonia/contra-hegemonia, também podendo ser representado pela universidade, por seu ambiente de ensino e aprendizagem, conhecimento e poder.

Chauí (2003) apresenta questionamentos pertinentes em relação à concepção teórica e prática do que é a universidade. A autora nos leva a pensar nas seguintes indagações: qual deve ser a relação entre universidade e sociedade? Como inserir a universidade na sociedade? A universidade brasileira absorve as ideias neoliberais?

Para Almeida (2019), as ideias neoliberais ampliam e aprofundam as desigualdades sociais e educacionais, distanciando a universidade da democratização do acesso à educação. Para reverter esse quadro, precisamos de ações inclusivas no ambiente educacional, sendo está uma das formas de amenizar a distância dos alunos de menor poder aquisitivo, especialmente os oriundos da escola pública, promovendo espaços de inclusão e cidadania também dentro das universidades.

Na universidade e na sociedade, esse debate precisa ganhar fôlego, pois novos sujeitos estão se inserindo no espaço universitário, ou seja, estamos vivendo um momento em que a educação popular constrói novos significados e uma nova cidadania para um público que, antes, de maneira reduzida, frequentava o espaço universitário, sobretudo os estudantes egressos da escola pública, isso representa mais inclusão na educação superior.

Ancorada nesse pensamento, a pesquisa trouxe como reflexões as seguintes questões: os estudantes pertencentes às classes menos favorecidas que estão tendo acesso à universidade exercerão de maneira mais intensa a sua cidadania pelo fato de buscarem aumentar seu nível de escolaridade? A universidade aceita e acolhe esses estudantes, ou impõe restrições concretas ou abstratas, materiais ou imateriais por serem oriundos da escola pública?

Concordamos com Mészáros (2005) quando afirma que o simples acesso à escola é condição necessária, mas não suficiente para retirar das sombras do esquecimento social milhões de pessoas, cuja existência só é reconhecida nos quadros estatísticos. O deslocamento do processo de exclusão educacional não se dá na questão do acesso à escola, mas dentro dela. O que está em jogo não é apenas a modificação de políticas públicas educacionais contra o apartheid social, mas a reprodução da estrutura de valores que contribui para perpetuar uma concepção de mundo baseada na sociedade mercantil. 
Relacionando o termo apartheid com a realidade educacional brasileira, vemos notoriamente a separação dos indivíduos a partir do seu grau de instrução, especialmente quando observamos as grandes desigualdades educacionais da população do Brasil, não apenas em relação à educação formal, mas também a informal. Por isso questionamos: qual o espaço do cidadão, para os estudantes da escola pública, nas universidades federais, especialmente na UFCG? Quem é o cidadão que está tendo acesso ao espaço acadêmico? Será que os estudantes da escola pública fazem parte desse espaço cidadão dentro da universidade? Será que os estudantes egressos da escola pública estão vivenciando a cidadania proposta pelo meio acadêmico, tendo direito ao espaço acadêmico garantido?

Segundo Tonet (2006), por meio de uma educação democrática e cidadã, é possível contribuir com os indivíduos, estimulando a sua participação no processo social. Isso supõe ampliar cada vez mais a elevação do acesso à educação formal e informal. Como afirma Freire (2007), "a educação vai além dos livros", uma vez que transforma a essência e a dignidade humana.

Para Santos (2002, p.56), “a cidadania sem dúvida se aprende. Ela se torna um estado de espírito, enraizado na cultura. A cidadania não é apenas um estado de espírito ou uma declaração de intenções, podendo possuir definições abstratas. Entretanto, para ser válida, deve poder ser ouvida e reclamada". Sobre isso, perguntamos à representante da Pró-Reitoria de Pesquisa e Extensão: de que forma a UFCG busca se aproximar da sociedade e promover cidadania? A sua resposta é apresentada a seguir:

Buscamos melhorar a qualidade da extensão desenvolvida pela Instituição. Surgindo novas demandas, apontadas pela própria sociedade nas áreas em que são desenvolvidos os projetos, e por consequência expandindo a cidadania (Entrevista com representante da Pró-Reitoria de Pesquisa e Extensão, Acervo da pesquisa, 2018).

Nessa linha de pensamento, temos um grande desafio para as universidades nesse momento, que é como mobilizar seus estudantes a lutarem por uma educação que lhes promova cidadania, bem como uma formação profissional de qualidade. Precisamos ter em vista que a educação deve proporcionar visões de mundo que permitam aos sujeitos pensar sobre sua realidade, por meio de uma relação dialógica, na busca da emancipação social (ALMEIDA, 2019).

Dessa maneira, perguntamos aos estudantes da UFCG se o fato de possuirmos, hoje, no Brasil, um sistema de cotas para a inserção dos estudantes no nível superior aumenta as chances de construir cidadania para os estudantes egressos da escola pública? De acordo com as respostas dos estudantes, $71 \%$ afirmaram que sim e $29 \%$ destacaram que não, como podemos ver no gráfico 3 . 
GRÁFICO 3: Promoção de cidadania para os estudantes egressos da escola pública por meio do sistema de cotas

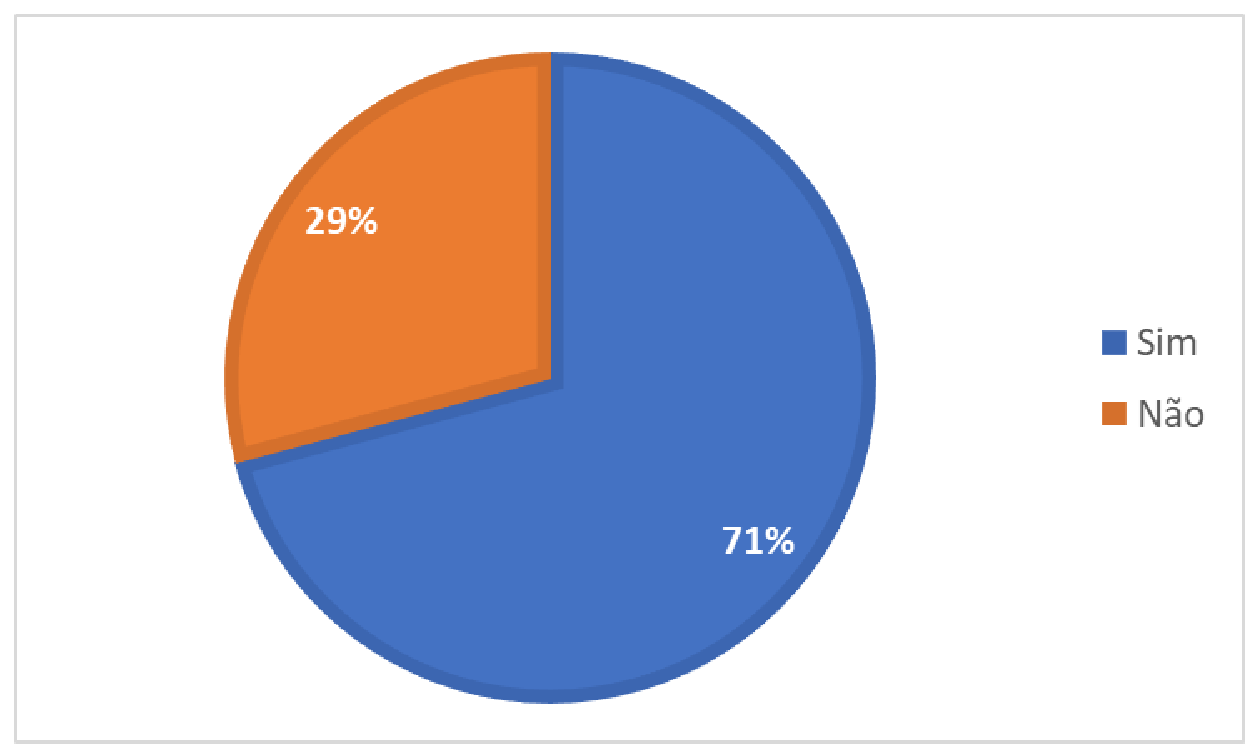

Fonte: Acervo da pesquisa, 2018.

Em ambas as respostas, positiva e negativa, os sujeitos da pesquisa concordam que, diante do cenário educacional brasileiro, as políticas educacionais, a exemplo do sistema de cotas, existem devido às fragilidades do ensino da escola pública, sendo extremamente importante melhorar a qualidade da educação pública, proporcionando uma formação básica escolar de qualidade para os alunos. Dessa maneira, as cotas representam, nas perspectivas dos referidos sujeitos, uma conquista para os alunos de menor poder aquisitivo, caracterizada por ser uma luta pela igualdade do direito de se educar.

Dentro desse contexto, o sistema de cotas é apresentado como uma das formas de ingresso dos discentes nas mais diversos IES, e na UFCG não é diferente, sendo este um desdobramento do reconhecimento por parte do Estado das medidas de ações afirmativas. Sobre isso, Lima (2014) destaca que a ação afirmativa tem o objetivo de criar oportunidades iguais de modo proativo. A prática mais conhecida de ação afirmativa é o sistema de cotas, que consiste em "estabelecer um determinado número ou percentual a ser ocupado em área específica por grupo(s) definido(s), o que pode ocorrer de maneira proporcional ou não, e de forma mais ou menos flexível" (LIMA, 2014, p. 19).

Perguntamos aos mesmos discentes da UFCG se as ações afirmativas são formas de reparar as desigualdades e contrastes educacionais. $87 \%$ responderam que sim e $13 \%$ disseram que não. Muitos alunos da escola pública pertencem a um contexto socioeconômico de pobreza e exclusão econômica, por isso, a partir da política de cotas, diversos estudantes estão adquirindo seu acesso na 
universidade através de políticas públicas educacionais, promovendo cidadania como uma conquista relevante para os estudantes das universidades públicas no Brasil, bem como na UFCG, em Campina Grande.

Para Santos (2002) a cidadania é mais do que uma conquista individual, pois consideramos que a luta pela cidadania não se esgota na confecção de uma lei. Assim, é primordial que o cidadão, a partir das conquistas obtidas, esteja em alerta para garantir e ampliar a sua cidadania. $\mathrm{O}$ cidadão precisa ser capaz de romper com os preconceitos e adquirir os instrumentos de realização eficaz para a conquista da liberdade. Sozinhos, ficamos livres, mas não podemos exercitar a nossa liberdade.

Em relação à consciência do cidadão trazida por Milton Santos (2002), perguntamos aos professores diretores de centros acadêmicos da UFCG, o que a universidade está fazendo para estimular tais centros e as unidades acadêmicas, a fim de permitir que se efetive a cidadania e a democracia para todos os estudantes. Um resumo das suas respostas é apresentado a seguir:

Na realidade, o Centro não tem muita autonomia para desenvolver projetos na busca dessa cidadania, ficam em sua maioria concentrado na Reitoria [...] Mas, devido a nossas limitações, essa cidadania fica um pouco comprometida. (Diretor do CCT/UFCG, Acervo da pesquisa, 2018).

A Universidade disponibiliza bolsas, restaurante, área de lazer, contudo não são suficientes para a demanda [...] (Diretor do CCBS/UFCG, Acervo da pesquisa, 2018).

[...] A Universidade, buscando reduzir a evasão. As questões relacionadas à evasão ocorrem por diversos fatores dos quais podemos citar: a transferência para outros cursos e Universidades/faculdades, problemas psicológicos tais como, a depressão e ansiedade, que podem ser causados pela pressão da própria Universidade, mais também por fatores que fogem a responsabilidade da Instituição (Diretor do CH/UFCG, Acervo da pesquisa, 2018).

Temos o grupo PET. Na primeira semana de aula, recepcionamos os novos estudantes, acolhendo-os. Os estudantes conhecem todas as instalações, laboratório e infraestrutura, todos os espaços de pesquisa; oferecemos também cursos de nivelamento (Diretor do CEEI/UFCG, Acervo da pesquisa, 2018).

Buscamos com muita responsabilidade deixar nossa contribuição na área da educação de nível Superior, sobretudo para essa região polarizada por Campina Grande, além de ultrapassar o próprio estado da Paraíba. Os trabalhos desenvolvidos e pesquisas são aplicados na nossa região, já que temos um problema grande com a desertificação, infraestrutura, abastecimento d'agua, entre outros (Diretor do CTRN/UFCG, Acervo da pesquisa, 2018).

$\mathrm{Na}$ fala dos entrevistados, percebemos que existem ações realizadas pelos centros acadêmicos da UFCG, no sentido de acolher os estudantes e proporcionar cidadania. No entanto, os professores relatam as limitações que existem, especialmente devido a uma questão hierárquica entre a Reitoria da universidade e tais centros.

Baptistela (2015, p.11) destaca que a cidadania pode ser entendida, seguindo o pensamento da filósofa Hannah Arendt (1906-1975) como “o direito a ter direitos”. A autora destaca que só 
conseguimos perceber a existência de um direito a se ter quando pertencemos a uma comunidade organizada, quer dizer, um espaço que é comum a todos e no qual as ações e as palavras de cada sujeito são significativas e aptas a instituir direitos.

Pensando na relação dos direitos do cidadão, Santos (2002) apresenta uma provocação: há cidadãos nesse país? Ele destaca que o termo cidadão tem seu sentido real muitas vezes esquecido, ao nos convidar a uma reflexão sobre quantos habitantes são cidadãos? Quantos nem sequer sabem que não o são? Dessa forma, o autor acrescenta que o simples fato de nascer investe ao indivíduo uma ideia inalienável de direitos, formalizada pelo fato de ingressar na sociedade.

Essas não são perguntas simplistas, tendo em vista que existe, em suas indagações, muito mais do que questionamentos. Percebemos que o mencionado autor apresenta uma preocupação no tocante à consciência dos indivíduos sobre as questões inerentes à cidadania, à sociedade, à liberdade e ao poder que cada pessoa possui. Dessa maneira, entender o espaço do cidadão é algo que deve ser analisado em sua totalidade social, considerando-o como processo dialético a partir das dimensões sociais, culturais, educacionais, de identidade, das histórias de vida e da representação desses elementos para a formação de uma consciência social.

\section{PERMANÊNCIA DOS ESTUDANTES EGRESSOS DA ESCOLA PÚBLICA NA UFCG}

Buscamos verificar, além do acesso dos estudantes egressos do ensino público na UFCG, quais mecanismos são usados para contribuir com a permanência desses estudantes em seus cursos. Para isso, conhecemos as perspectivas de professores, estudantes e representantes da Pró-Reitorias de Assuntos Comunitários (PRAC).

Pensando nisso, questionamos quais os aspectos que concorrem para dificultar o acesso e a permanência dos estudantes vindos da escola pública segundo os diretores de centros da UFCG? O método de Análise de Similitude (AS) ou de semelhança nos possibilitou localizar coocorrências existentes entre as palavras, indicando suas conexidades, por meio do programa IraMuTeQ, no intuito de construirmos uma análise mais detalhada, como podemos verna figura 1 . 
Figura 1: Mecanismos da UFCG para realizar o acesso e a permanência dos estudantes

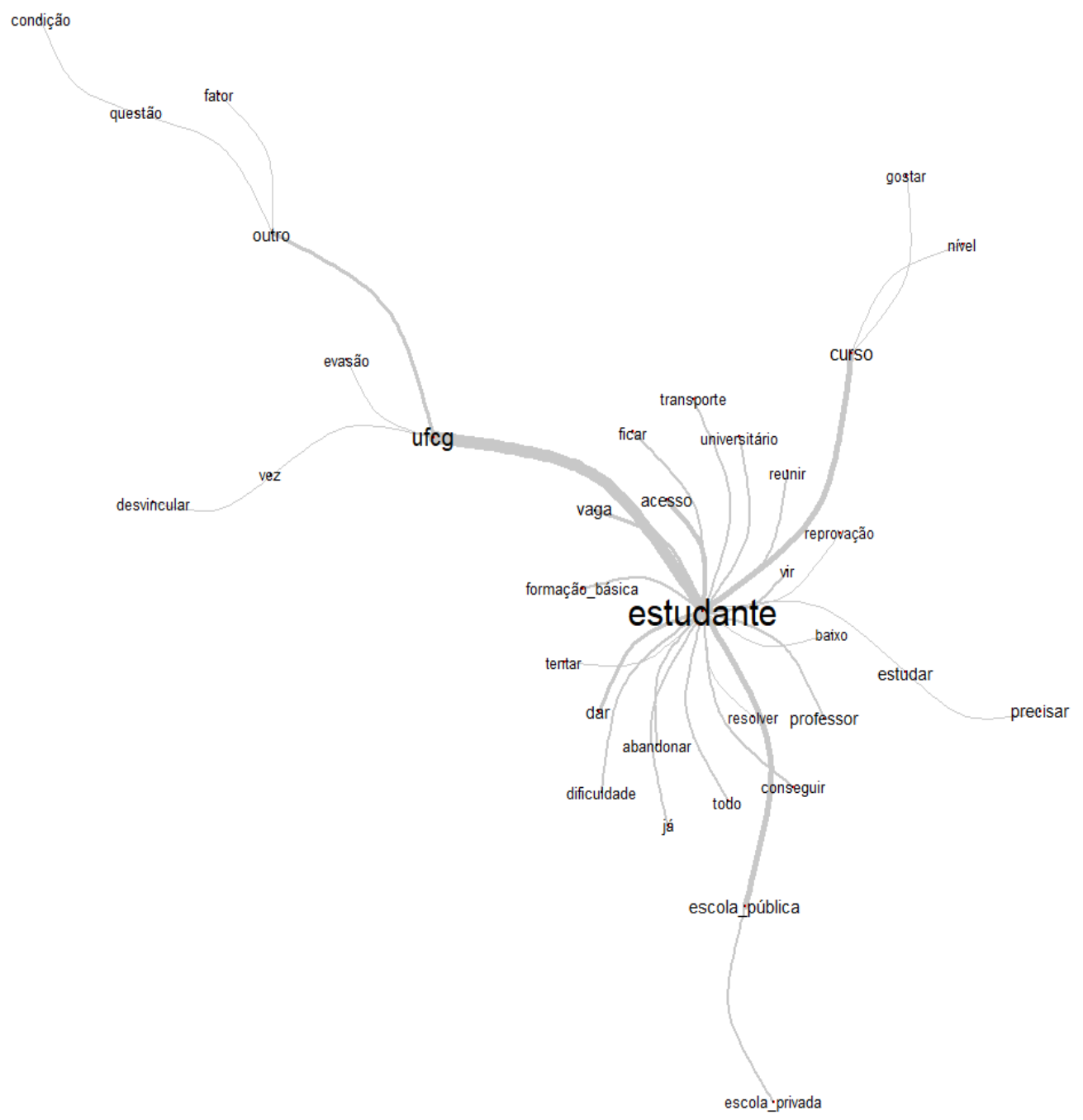

Fonte: Acervo da pesquisa, 2019.

Dessa forma, a palavra com maior evocação pelos respondestes foi "estudante". A partir dela, temos três coocorrências com maiores frequências: com os termos "UFCG" (sugiram os termos "vaga”, “evasão”, “outro fator”, “desvincular”, “condição”), “curso” ("gostar”, "nível”) e "escola pública" (“conseguir" e "escola privada"). O programa filtrou outras palavras importantes com menor frequência, sendo elas "professor", "abandonar", "formação básica”, "reprovação", “acesso", "transporte", "Reuni”, "dificuldade", "estudar" e "precisa".

Observamos que, na UFCG existe inclusão e acesso para os estudantes da escola pública, porém, quando pensamos em permanência dos discentes nos cursos de graduação, observamos a 
preocupação com a evasão. Para Almeida e Santos (2018), a evasão nas universidades não ocorre apenas com os estudantes vindos da escola pública, ou seja, também ocorre com os oriundos da escola privada, causando sérios problemas, como, por exemplo, o aumento das vagas ociosas.

Outro fator em destaque para a não permanência dos alunos é o nível de formação escolar básica. Em algumas ocasiões, esse nível não proporciona aos estudantes subsídios totais para acompanhar as aulas. Os respondestes mencionaram também que é necessário que os estudantes gostem do seu curso para superar as múltiplas dificuldades (financeira, de ensino e aprendizagem, motivacional, de acolhimento, dentre outras) e não abandonar os estudos. Fatores psicológicos e emocionais também foram apontados pelos estudantes e docentes conforme a pesquisa de Oliveira (2017), sendo este um dos problemas motivadores da evasão de uma parcela importante de alunos da UFCG, segundo dados do CCBS/UFCG.

Perguntamos aos professores diretores dos cinco centros da UFCG, quais mecanismos a instituição está realizando para estimular a permanência e diminuir a evasão dos estudantes oriundos da escola pública. Essa questão foi analisada pelo método de Análise de Similitude, buscando, assim, filtrar e valorizar as expressões mais evocadas para essa indagação, na perspectiva dos professores.

A palavra que obteve maior destaque foi "estudante", ficando assim no centro do gráfico. A partir dela, foram construídas cinco coocorrências, com os seguintes termos: "evasão", "permanência", "bolsas", "dificuldades" e "curso". A palavra "evasão" foi muito evocada pelos professores, sendo associada às expressões "disciplina" e "motivo". Outro termo de coocorrência foi "permanência", associado às palavras "centro" e "universidade"; "bolsas" foi outra expressão de grande coocorrência; "dificuldades", termo destacado com uma forte frequência, foi associado às palavras "social" e "lacunas". Por fim, a palavra "curso" foi outro termo com grande utilização pelos professores, sendo relacionado às palavras "precisam" e "manter", como podemos observar na figura 2.

Figura 2: Mecanismos utilizados para estimular a permanência e diminuir a evasão. 


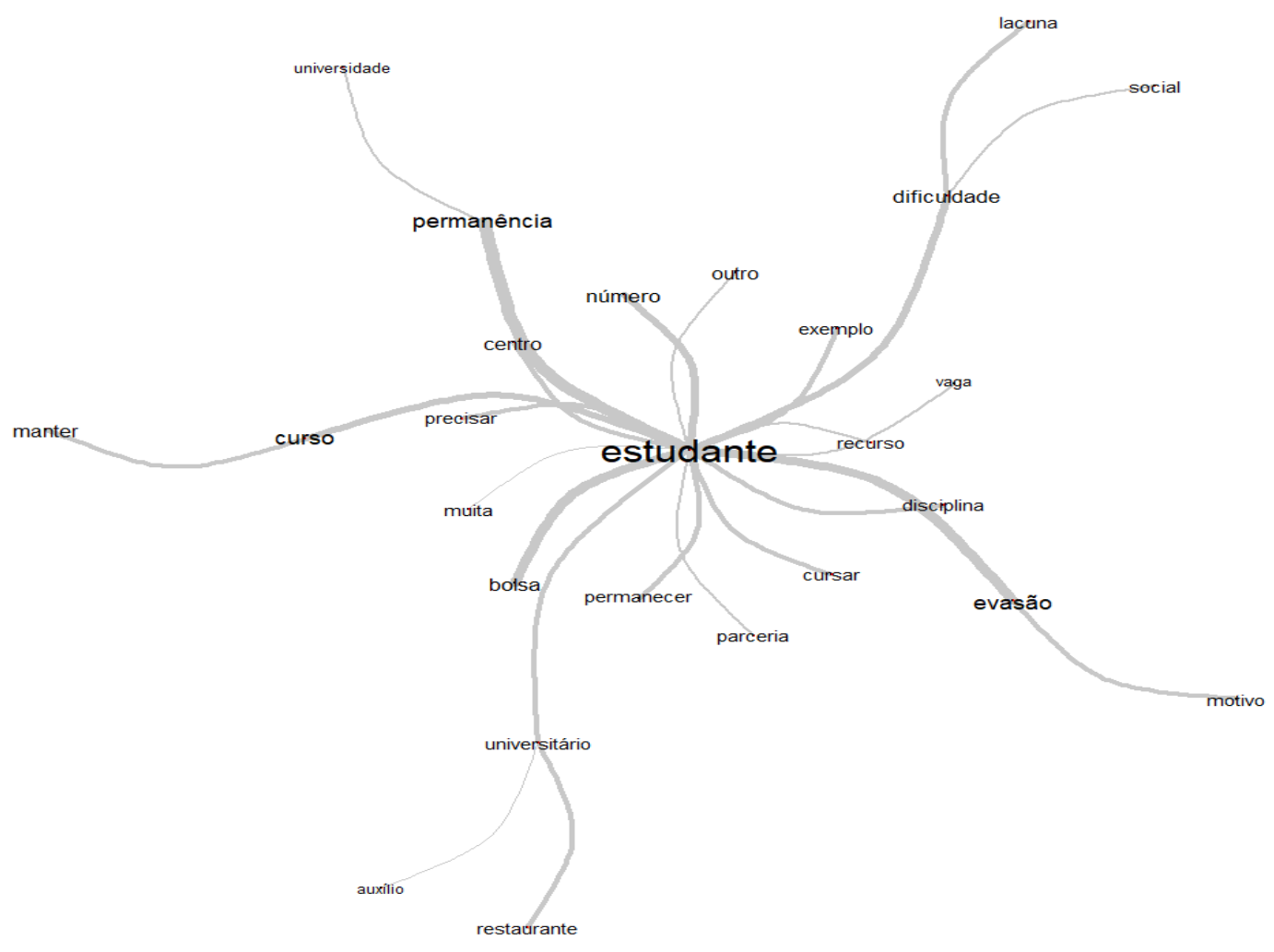

Fonte: Acervo da pesquisa, 2019.

Podemos observar que, de acordo com a fala dos entrevistados, os mecanismos utilizados pela UFCG para estimular a permanência e diminuir a evasão dos estudantes passam por algumas questões que merecem ganhar uma maior reflexão dentro da instituição, tendo em vista que os estudantes de baixa renda, oriundos da escola pública, são os que possuem maiores dificuldades financeira para permanecerem na universidade.

Nessa perspectiva, manter-se na universidade é um desafio cada vez maior para os estudantes, em especial os de baixa renda. Assim, a Assistência Estudantil tem sido um dos suportes mais relevantes diante das desigualdades econômicas desses sujeitos, estimulando a sua permanência na instituição. Os obstáculos se tornam mais evidentes para os discentes que não recebem nenhum auxílio estudantil. Por isso, as políticas educacionais de Assistência Estudantis têm sido primordiais para estimular a permanência e a não evasão dos discentes de menor poder aquisitivo na UFCG.

Outra dificuldade vivenciada pelos estudantes está ligada às lacunas deixadas durante a sua formação escolar básica. Esse problema é outro agravante que alimenta a não permanência na universidade. O termo "precisa" ligado à palavra "curso" foi ressaltado para enfatizar que a 
universidade precisa pensar meios que evitem a evasão. O termo "manter" também associado a "curso" está relacionado aos recursos insuficientes para promover uma maior assistência estudantil para os estudantes de baixa renda, ajudando-os a se manterem na universidade.

Esse e outros motivos, segundo os professores diretores dos centros, provocam a não permanência dos estudantes na UFCG. Para o enfrentamento dessa problemática, foram ressaltadas as palavras "outro", "recurso", "vaga”, "número", "cursa”, “disciplina”, "parceria”, "permanecer", "auxilio" e "restaurante". Esses termos compõem a relação entre a permanência e a redução da evasão.

De acordo com as entrevistas feitas com os professores, essas palavras são relevantes, pois ressaltam que existe o acesso à universidade para os estudantes. Entretanto, a permanência dos estudantes perpassa alguns problemas que só podem ser solucionados com: Políticas Educacionais de inclusão, permanência e Assistência Estudantil (ampliação de vagas no restaurante universitário, auxílio moradia e /ou transporte, bolsa PAEG e outras ações). Segundo os docentes entrevistados, outro fator importante é parcerias com órgãos públicos e privados (por meio de estágios e outros formatos de ações junto ao ensino, pesquisa e extensão), buscando aproximar os estudantes do mercado de trabalho, fato este que estimularia ainda mais a sua permanência no ensino superior.

Na perspectiva de Gisi e Gurgel (2016), além das dificuldades de acesso à educação superior relacionadas, em especial, às de ordem econômica, ainda existem as deficiências decorrentes da trajetória escolar de muitos estudantes. Muitos dos que conseguem o ingresso na educação superior abandonam o curso antes do seu término, pois são estudantes que não conseguem concluir seu curso, quer em instituições públicas, quer em instituições privadas, já que, em ambas as situações, observa-se a evasão.

Pensando nisso, perguntamos aos estudantes, se eles sentiram dificuldades acadêmicas devido à sua formação escolar básica. Caso a resposta fosse positiva, questionamos se houve atenção da universidade em relação a isso, como podemos ver na figura 3. Dessa forma, a palavra com maior evocação pelos respondestes foi "sim". A partir dela, observamos 5 ramificações em torno das palavras "professor", "universidade", "dificuldade", "estudante" e "minha". Em relação ao termo "professor", a palavra foi associada a "procurar", "dificuldades financeiras", "sentir", "falta", "principalmente" e "família".

A outra palavra que possuiu uma grande frequência foi "universidade"; a partir desse termo, os estudantes destacaram as palavras "atenção", "cobrança", "problemas”, "estudar", "tudo", "assistência" e "concluir". Em relação à palavra "estudante" (uma expressão com grande frequência 
no gráfico), foram destacados os vocábulos "manter", "curso", "escola", "questão", "possuir" e "acadêmico". Também teve destaque foi "dificuldade"; a partir dela, foram usados os termos “muita”, "buscar", “estudo”, “disciplina”, “cálculo" e "superar”.

Foi ressaltada com frequência a palavra "minha"; a partir dela, os estudantes destacaram as palavras "leitura", "desistir", "ensino médio", "compreensão" e "maior". A palavra "minha" tem uma conotação de posse, de algo pessoal, individual.

Em relação à permanência na UFCG, detectamos que alguns cursos estão realizando ações e estratégias para estimular os estudantes a continuarem estudando. Segundo os relatos de professores e estudantes, alguns projetos buscam combater a evasão estudantil, bem como a reprovação, porém, tais ações ficam situadas apenas em suas Unidades Acadêmicas, e outras coordenações não tem conhecimento dessas ações. Observamos que, se ocorresse um maior diálogo entre as Unidades Acadêmicas, no sentindo de trocarem as suas experiências dentro da UFCG, essa ação poderia ajudar os cursos a encontrarem mecanismo para motivar os estudantes a não abandonarem a universidade. Isso pode se dá por meio da expansão dos fóruns de diálogo e reflexão entre as coordenações.

Figura 3: Dificuldades acadêmicas ao ingressar na universidade devido à sua base escolar.

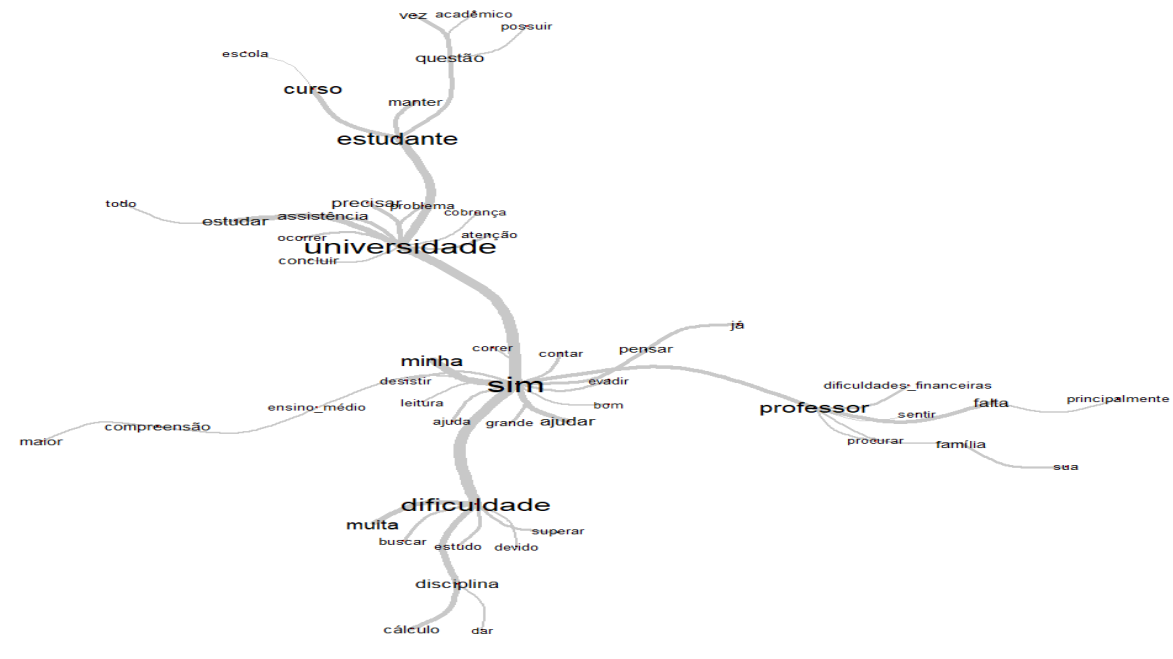

Fonte: Acervo da pesquisa, 2019.

Vemos que os estudantes que chegam à universidade com problemas em relação à sua formação escolar não são exclusivos da UFCG. Desse modo, devem ser pensadas políticas educacionais que fortaleçam a educação básica e, por conseguinte, proporcionem aos estudantes um maior domínio de conteúdos da educação escolar. A universidade deve pensar e efetivar 
mecanismos que possam dar subsídios para os estudantes que necessitam de mais atenção em determinados componentes curriculares, especialmente em algumas disciplinas que necessitam de uma maior profundidade dos conteúdos, construindo estratégias que busquem acolher esses estudantes, incentivando-os a superarem as lacunas da sua formação escolar.

Para Freire (2007, p. 91), se a educação não é alavanca pelas transformações sociais, estas não se fazem sem ela. É premente o fato de que a educação possibilita a compreensão do papel de cada indivíduo no mundo e de sua inserção na história. A educação promove a construção de uma consciência que faz com que o homem mergulhe na sua própria realidade, a partir de uma consciência que o leve a desenvolver processos educativos (BEISIEGEL, 2008).

Logo, a educação brasileira tem, em sua história cicatrizes perversas, marcadas por grandes desigualdades econômicas e sociais. As desigualdades também são visíveis no direito à educação de qualidade (nos diversos níveis, inclusive no ensino superior). Os problemas educacionais brasileiros se tornam cada dia mais complexos, e as políticas educacionais muitas vezes são incapazes de solucionar esses problemas, evidenciados pela: baixa qualidade da educação escolar pública, falta de infraestrutura e materiais didáticos, contínuos cortes dos investimentos educacionais (que ocorre nos diversos níveis de educação), juntamente com uma formação de professores que possui fragilidades teóricas, pedagógicas e metodológicas.

Os estudos, as iniciativas e as pesquisas no campo da Geografia podem e devem estudar a geografização dos fenômenos educacionais, envolvendo ações que busquem entender a produção dos espaços e dos territórios com diversas funcionalidades, como, por exemplo, os espaços da universidade, pois este é um lugar de conhecimento e formação profissional.

\section{CONSIDERAÇÕES FINAIS}

A escola e a universidade são espaços considerados relevantes para a sociedade, já que, neles, ocorre a construção dos processos educativos. No Brasil, mais do que nunca precisamos profundamente valorizar a educação, especialmente quando vivemos grandes incertezas e dúvidas sobre os caminhos da educação pública (em especial a universitária). Por isso, por meio da educação, poderemos lutar para termos as armas que nos ajudaram a construir um país mais justo, buscando, assim, a emancipação da sociedade.

Por isso, devemos pensar: qual deve ser a postura das intuições de ensino superior e dos seus docentes diante das dificuldades de acesso e permanência dos estudantes, em especial os oriundos da escola pública? Com essa provocação, vemos que existe um discurso por parte de alguns 
docentes que destacam que esse problema não é seu ou da instituição de ensino superior, pois a raiz encontra-se no ensino básico e este entrave só pode ser solucionado no espaço escolar.

O problema existe no âmbito da educação superior e enquanto professores universitários temos que pensar nele, não podemos ignora-lo, pois, a universidade é um espaço de reflexão, caso contrário continuaremos a ter problemas de reprovação, evasão, vagas ociosas, dentro outros entraves.

As dificuldades em relação à formação escolar básica vivida pelos estudantes egressos nas universidades, quando não são superadas, formam um dos motivos que alimentam a desistência dos estudantes, juntamente com a cobrança maior dos professores, a cada nova disciplina do curso. Nesse sentido, a universidade deve conhecer essas dificuldades e procurar ajudá-los a superarem esse problema. Vimos essa preocupação nos relatos de muitos professores diretores de centro da UFCG.

Os docentes precisam dialogar e encontrar caminhos diante dessa realidade, cumprindo o papel da universidade de formar profissionais para atuar nas múltiplas áreas e situações diversas da sociedade, buscando promover a cidadania e a profissionalização dos seus sujeitos, sendo está uma contribuição valorosa para a sociedade.

Diante da relevância do tema, buscamos mobilizar o interesse dos pesquisadores da Geografia e de outras áreas afins, com o propósito de construirmos espaços menos desiguais junto aos ambientes educacionais, promovendo cidadania e emancipação por meio do acesso e da permanência mais democráticos ao ensino superior. Para isso, a universidade pública é a nossa peça-chave, pois é um ambiente primordial para a construção de cidadania, democracia, inclusão e educação.

Dessa forma, a ideia de uma universidade pública para todos ganha espaço com a expansão educacional, especialmente com a implantação do REUNI. Entretanto, precisamos destacar que, mesmo com o grandioso aumento de cursos e campi, os números não são suficientes para atender os estudantes ausentes do ensino superior, cuja inclusão se faz a um ritmo demasiadamente inferior às necessidades da sua demanda real (PRESTES; JEZINE; SCOCUGLIA, 2012).

Concluímos nossa investigação com o sentimento de que ainda temos um longo caminho a percorrer; porém, para esse momento, esperamos que a pesquisa estimule proposituras para darmos continuidade a essa reflexão, pois há muito a se investigar: esse é um movimento contínuo e não linear. Assim, é nosso intuito que esse estudo promova uma expansão de pesquisas sobre essa temática e que a Geografia seja pensada diante da construção de espaços e territórios, inclusive 
dentro dos ambientes em que se faz presente a educação, como é o caso das universidades, como é o caso da UFCG. Dessa maneira, buscamos despertar o interesse sobre a educação como propósito de construir cidadania e emancipação, dentro e fora do ambiente acadêmico.

Portanto, a universidade é um espaço que possui uma força transformadora para diversos estudantes que buscam não apenas um diploma, mas emancipação. Precisamos defender a universidade pública e de qualidade para o povo, ou seja, para todos aqueles que buscam ter acesso a esse espaço. Por isso, os desafios persistirão, pois esse é um jogo que envolve interesses sociais e políticos, porque a educação, primordialmente, é um bem público e deve ser construída numa perspectiva popular, para o povo e com o povo.

\section{REFERÊNCIAS}

ALMEIDA, J. N. Acesso e permanência de estudantes egressos da escola pública no ensino superior: um olhar crítico para as espacialidades na Universidade Federal de Campina Grande, Campus Sede. 233 f. Tese (Doutorado em Geografia) - Programa de Pós-Graduação em Geografia, Universidade Federal da Paraíba, Recife, 2019.

ALMEIDA, J. N.; SANTOS, F. K. S. Universidade Federal de Campina Grande: contribuições na educação, ciência e tecnologia em uma cidade média Nordestina. Anais eletrônicos do XIX Encontro Nacional de Geografia. 2018. Disponível em: http://www.eng2018.agb.org.br/site/anaiscomplementares2?AREA=20\#J. Acesso em: 28 jul. 2020. BAPTISTELA, T. O conceito de cidadania de Hannah Arendt: "o direito a ter direitos". Anais da semana acadêmica Fadisma Entrementes. 2015. Disponível em: http://sites.fadisma.com.br/entrementes/anais/wp-content/uploads/2015/08/o-conceito-de-cidadaniade-hannah-arendt_\%E2\%80\%9Co-direito-a-ter-direitos\%E2\%80\%9D.pdf. Acesso em: 28 jul. 2020.

BEISIEGEL, C. R. Política e Educação popular: a teoria e a prática de Paulo Freire no Brasil. São Paulo: Liber Livro, 2008.

BRASIL. Decreto n. 6.096, de 24 de abril 2007. Institui o Programa de Apoio a Planos de Reestruturação e Expansão das Universidades Federais - REUNI. Diário Oficial da União: seção 1, Brasília, DF, Ano CXLIV, n. 79, p. 7, 25 abr. 2007. 
BRASIL. Decreto n. 7.234, de 19 de julho de 2010. Dispõe sobre o Programa Nacional de Assistência Estudantil - PNAES. Diário Oficial da União: seção 1, Brasília, DF, Ano CXLVII, n. 137, p. 5, 20 jul. 2010.

CATANI, A M.; HEY, A. P. GILIOLI, R. S. P. PROUNI: democratização do acesso às instituições de ensino superior? Educar em Revista, Curitiba, n. 28, p. 125-140, 2006.

CAMARGO, B. V. JUSTO, A. M. O IRaMuTeQ: um software gratuito para análise de dados textuais. Temas em Psicologia, Ribeirão Preto - SP, v. 21, n. 2, p. 513-518, 2013.

CHAUÍ, M. A universidade pública sob nova perspectiva (comunicação proferida na abertura da $26^{\text {a }}$ Reunião Nacional da ANPEd, em outubro de 2003). Revista Brasileira de Educação, n. 24, p. 5-15, 2003.

DOURADO, L. F.; OLIVEIRA, J. F.; SANTOS, C. A. A qualidade da educação: conceitos e definições. Brasília - DF: INEP, 2007.

DOURADO, L. F. Reforma do estado e as políticas para a educação superior no Brasil nos anos 90.

Educação \& Sociedade, Campinas - SP, v. 23, n. 80, p. 234-252, 2002.

FREIRE, P. Pedagogia da autonomia: saberes necessários à prática educativa. Rio de Janeiro: Paz e Terra, 2007.

GISI, Maria Lourdes. PEGORINI, Diana Gurgel. As políticas de acesso e permanência na educação superior: a busca da igualdade de resultados. In: Revista online de Política e Gestão Educacional. v. 20, n. 1 2016. p. 21-37. Disponível em 〈https://periodicos.fclar.unesp.br/rpge/article/view/9390>. Acesso em: 22 jan. 2019.

INEP. Censo da Educação Superior 2016. 2016. Disponível em: http://download.inep.gov.br/educacao_superior/censo_superior/documentos/2016/notas_sobre_o_ce nso_da_educacao_superior_2016.pdf. Acesso em: 28 jul. 2020.

LIMA, M. E. O.; NEVES, P. S. da C.; SILVA, P. B. A implantação de cotas na universidade: paternalismo e ameaça à posição dos grupos dominantes. Revista Brasileira de Educação, v. 19, n. 56, 2014. Disponível em: http://www.anped.org.br/site/rbe Acesso em: 10/12/2018.

MÉSZÁROS, I. A educação para além do capital. Tradução de Isa Tavares. São Paulo: Boitempo, 2005. 
NASCIMENTO, C. M. Assistência estudantil e contrarreforma universitária nos anos 2000. 158 f. Dissertação (Mestrado em Serviço Social) - Programa de Pós-Graduação em Serviço Social, Universidade Federal de Pernambuco, Recife, 2013.

NEVES, P. S. C. A política de reserva de vagas da Universidade Federal de Sergipe para alunos de escolas públicas e não brancos: uma avaliação preliminar. O impacto das cotas nas universidades brasileiras (2004-2012). Salvador: CEAO, 2013.

OLIVEIRA, K. P. S. Sofrimento psíquico em acadêmicos: um despertar para a saúde mental dentro da academia. Campina Grande: Editora da UFCG, 2017.

PALÁCIO, P. P. Políticas de acesso e permanência do estudante da universidade federal do Ceará (UFC). 123 f. Dissertação (Mestrado Profissional em Políticas Públicas e Gestão da Educação Superior) - Programa de Pós-Graduação em Políticas Públicas e Gestão da Educação Superior, Universidade Federal do Ceará, Fortaleza, 2012.

PRESTES, E. M. T.; JEZINE, E.; SCOCUGLIA, A. C. Democratização do Ensino Superior Brasileiro: O caso da Universidade Federal da Paraíba da Paraíba. Revista Lusófona de Educação, Lisboa, v. 21, n. 21, p. 199-218, 2012.

SANTOS, M. O espaço do cidadão. São Paulo: Nobel, 2002. (Coleção Espaços)

SÂMARA, B.S.; Barros, C.J. Pesquisa de marketing: conceitos e metodologia. São Paulo: Prentice Hall, 1997.

SERPA, A. Ser lugar e ser território como experiências do ser-no-mundo: um exercício de existencialismo geográfico. Geousp - Espaço e Tempo, São Paulo, v. 21, n. 2, p. 586-600, 2017.

TONET, I. Educação e formação humana. Ideação, Foz do Iguaçu - PR, v. 8, n. 9. p. 9-21, 2006. 